\title{
ACONTECIMENTOS MEDIÁTICOS: PROMOTORES DE MUDANÇAS SOCIAIS, OU SIMULACROS DE FATOS EM TEMPO REAL?
}

\section{MEDIA EVENTS: SOCIAL CHANGING PROMOTERS, OR REAL TIME FACT SIMULACRA?}

\author{
Lidiane Santos de Lima Pinheiro*
}

\begin{abstract}
RESUMO
Os grandes acontecimentos funcionam como pano de fundo para preocupações sociais e debates potencialmente promotores de mudanças. Portanto, é importante se conscientizar do papel dos dispositivos que participam da sua construção discursiva, tais como os meios de comunicação de massa, que dão visibilidade às questões que se desenham como fundamentais para o espaço público. Diante disso, o presente artigo investiga se o acontecimento mediático (previamente planejado e organizado para a transmissão televisiva) constituiria efetivamente uma experiência pública capaz de promover mudanças sociais, ou se ele seria apenas um simulacro. Visando a esclarecer o fenômeno de mediatização do acontecimento e seu processo de produção discursiva, este trabalho revisa as noções de acontecimento e acontecimento mediático e problematiza a tese sobre a intervenção televisiva como responsável pela possível redução do "acontecimento" a “fato”.
\end{abstract}

Palavras-chave: Acontecimento mediático. Discurso. Televisão.

\begin{abstract}
The big events work as basis of social worries and potentially debates that promote changes. Therefore, it's important to know the function of the building discursive devices,such as means of mass communication, which shows visible facts that design like fundaments to public space. Hence, this article inquire if the media event (planned and organized previously to TV transmission) would effectively constitute a public experience that can foment social changes or if it would be only a simulacrum. In order to enlighten the event of mediatization phenomenon and its process of discursive production, this work reviews the notions of event and media event and problematize the thesis about television intervention whereby responsible for feasible cutback from "event" to "fact".
\end{abstract}

Keywords: Media event. Discourse. Television.

\footnotetext{
* Doutora em Comunicação e Cultura Contemporâneas pela Universidade Federal da Bahia (UFBA), mestre em Literatura e Diversidade Cultural pela Universidade Estadual de Feira de Santana (UEFS) e graduada em Comunicação Social - Relações Públicas pela Universidade do Estado da Bahia (UNEB). Professora assistente do curso de Comunicação Social - Relações Públicas da UNEB. Email: <lidicom@ig.com.br>
} 


\section{Introdução}

O que é "acontecimento"? Responder a esta questão foi uma das propostas da revista Communication, número 18, de 1972, dirigida por Edgar Morin, após longo período de silêncio das Ciências Sociais em relação ao tema.

A unicidade que caracteriza o acontecimento parecia contrária à necessidade de repetição e regularidade do objeto científico. Logo, o privilégio dado às estruturas pelos historiadores de longa duração e demais estruturalistas não possibilitou suficientemente o desenvolvimento da problemática do acontecimento. Para o modelo estrutural, que estuda as relações funcionais entre elementos de um sistema estável, o caráter inesperado do acontecimento deveria ser reduzido, bem como seu poder de ruptura e de surpresa, a fim de pensá-lo como sintoma de uma estrutura englobante, ou para colocá-lo num macro-contexto que desse a ele sentido. Para os autores que seguem tal modelo, só com a banalização da sua força de ruptura o acontecimento poderia ser amalgamado e transformado em objeto de Ciências Sociais.

Com a filosofia, o paradigma construtivista e outras abordagens contemporâneas, o estudo do acontecimento voltou a frequentar as pesquisas em Ciências Sociais e História. Hoje o tema é resgatado e seu campo de estudo alargado.

Nas investigações em Comunicação Social, o acontecimento é focalizado, principalmente, quando se trabalha com valores-notícia. Busca-se definir os critérios de noticiabilidade para eleger determinados eventos como “jornalísticos” e diferenciá-los das ocorrências "banais”. Porém, com as pesquisas de Katz e Dayan (1992), outro tipo de acontecimento passou a ser observado pelos estudos dos media: o acontecimento mediático ${ }^{1}$.

Previamente planejado e organizado para a transmissão televisiva, o acontecimento mediático é um grande evento cuja cobertura ao vivo asseveraria à audiência a experiência de vivenciar um momento histórico. Contudo, alguns autores (ROMANO, 1998; ARQUEMBOURG-MOREAU, 2003) vêm questionando a compatibilidade desse tipo de ocorrência

\footnotetext{
1 Não ignoramos outras tipologias de acontecimento estudadas pelos pesquisadores de Ciências Sociais Aplicadas: pseudo-acontecimento, metaacontecimento etc. Apenas não as abordaremos, para não sairmos do foco deste trabalho.
}

com o conceito de acontecimento. A transmissão televisiva daria conta do acontecimento? O acontecimento mediático constituiria efetivamente uma experiência pública ou seria apenas um simulacro? Os regimes de temporalidade da televisão e do acontecimento seriam compatíveis?

A fim de resgatar tal discussão e proporcionar possíveis respostas às questões levantadas, revisaremos inicialmente alguns estudos sobre a noção de acontecimento; em seguida, trabalharemos com o conceito de acontecimento mediático, tendo como caso exemplar o último casamento real (príncipe William e Kate Middleton), e apresentaremos algumas teses sobre a intervenção televisiva como forma de reduzir a "fato" o pretenso "acontecimento". Por fim, colocaremos em questão tais perspectivas, visando, entretanto, a não apenas oferecer mais uma leitura sobre o assunto, mas a ajudar a esclarecer o próprio fenômeno de mediatização do acontecimento.

\section{O que é acontecimento?}

Termo polissêmico, complexo e incerto, o acontecimento, no sentido amplo, pode ser considerado como tudo o que acontece e que está marcado no tempo, tendo uma origem e um fim. No sentido restrito relaciona-se ao excepcional, ao imprevisto: desastres, catástrofes, crises etc. Define-se, assim,

par rapport à une norme, où il est l'a-normal, c'està-dire l'exceptionnel et/ou le déviant, dans le cas où norme signifie determination ou probabilité, l'aléatoire ou l'improbable. La presse, par exemple, sélectionne comme événements ce qui est écart par rapport à la norme, que ce soit au-dessus de la norme 2 . (MORIN, 1972b, p. 177).

O nascer do sol, por exemplo, é um acontecimento no sentido amplo, mas não no restrito. Interessa-nos aqui o sentido restrito, como explicado também por Paul Ricoeur (1991, p. 43): “tout ce qui arrive ne fait pas événement, mais seulement ce qui surprend notre attente, ce qui est intéressant, ce qui est importante.”3

\footnotetext{
2 “por relação a uma norma, onde ele é o anormal, ou seja, o excepcional e/ou o que desvia, no caso onde a norma significa determinação ou probabilidade, o aleatório ou o improvável. A imprensa, por exemplo, seleciona como acontecimento o que é desvio por relação à norma, que esteja além da norma.” (MORIN, 1972b, p. 177, tradução nossa).

3 “nem tudo o que acontece é acontecimento, mas somente o que surpreende nossa expectativa, o que é interessante, o que é importante.” (RICOEUR, 1991, p. 43, tradução nossa).
} 
Ao surpreender, o acontecimento faz descobrir uma regularidade própria a uma esfera social ou a um grupo de indivíduos: “L’événement, c’est le nouveau par rapport à l'ordre déjà institué. C'est en instaurant un nouvel ordre dans lequel l'événement sera compris que le sens réduit l'irrationalité principalle de la nouveauté.”4 (RICOEUR,1991, p. 43). Logo, o acontecimento é o que diferencia a situação final da inicial e sobre o qual refletimos na sua relação com o que se mantém, o que persiste.

Para Pierre Nora (1972, p.167), “comme la verité, l'événement est toujours révolutionnaire, le grain de sable dans la machine, l'accident qui bouleverse et prend au dépourvu." 5 Segundo Nora, o acontecimento é sempre revolucionário, pois representa ruptura e novidade diante de um sistema social estabelecido, cujos poderes instituídos procuram se perpetuar e, consequentemente, negar o acontecimento. Isso porque o acontecimento desequilibraria a base sob a qual eles se fundamentam. Mas, como bem reflete Miquel Rodrigo Alsina (2009), não é que o acontecimento seja exatamente negado por tais poderes, mas, certamente, controlado.

Conforme Edgar Morin (1972a, p. 17), "tout élément peut être consideré comme événement dans la mesure où on le considère situé dans l'irréversibilité temporelle, comme une manifestation ou actualisation, c'est-à-dire en fonction de son apparition et de sa disparition, comme en fonction de sa singularité.” A singularidade, contudo, só pode ser assim caracterizada ao relacionarmos o acontecimento com algum sistema: "la nature accidentelle, aléatoire, improbable, singulière, concrète, historique de l'événement dépend du système selon lequel on le considere."” (MORIN, 1972a, p.17).

\footnotetext{
${ }_{4}$ “O acontecimento é o novo em relação à ordem já estabelecida. É instaurando uma nova ordem na qual o acontecimento será compreendido, que o sentido reduz a irracionalidade principal da novidade.” (RICOEUR, 1991, p. 43, tradução nossa).

5 "como a verdade, o acontecimento é sempre revolucionário, o grão de areia na máquina, o acidente que transtorna e pega o despreparado." (NORA, 1972, p.167, tradução nossa).

6 "todo elemento pode ser considerado como acontecimento na medida em que o consideremos situado na irreversibilidade temporal, como uma manifestação ou atualização, ou seja, em função de sua aparição e de seu desaparecimento, como em função de sua singularidade.” (MORIN, 1972a, p. 17, tradução nossa).

7 "a natureza acidental aleatória, improvável, singular, concreta, histórica do acontecimento depende do sistema segundo o qual o consideramos." (MORIN, 1972a, p.17, tradução nossa).
}

Para esclarecer o que foi dito no parágrafo anterior, usemos o mesmo exemplo do autor: as mortes no trânsito durante os fins de semana são apenas um elemento previsível no sistema estatístico-demográfico, mas são acontecimentos inesperados para os familiares das vítimas. Ou, pensando um exemplo a partir do campo de produção jornalística: a notícia de um assalto a uma agência dos correios de uma cidade do interior da Bahia será um acontecimento relevante para a população local e, portanto, para o jornal da região; mas, provavelmente, não o será para a imprensa nacional e, certamente, também não aparecerá nas páginas dos jornais internacionais. A noção de acontecimento se dá apenas por relação ao sistema que afeta, ratifica Morin (1972b), em outro artigo publicado na mesma revista.

Uma ocorrência pode ser um acontecimento para quem o desconhecia ou para quem com ele se surpreende, mas não para quem está habituado a tal fenômeno. Além disso, a transformação de uma ocorrência em acontecimento está relacionada com a sua utilidade para um indivíduo na organização de sua experiência (MOLES, 1972).

As pessoas consideram como importantes as ocorrências úteis para a demarcação do tempo (ritos de passagem, celebrações e outras marcas temporais partilhadas por um grupo), que se tornam referenciais para pensar o presente, o passado ou o futuro. Contudo, a demarcação do tempo a partir de fatos significativos é compartilhada socialmente. O homem, por viver em coletividades, padroniza a percepção do passado e do futuro e, assim, partilha de um tempo público. A elaboração do sentido desse tempo público se dá a partir de acontecimentos (públicos), que se tornam conhecidos através do efeito multiplicador do trabalho dos historiadores, jornalistas etc. (MOLOTCH; LESTER, 1996).

O que acontece, pensando o singular em Ciências Sociais, é a "singularização" da ocorrência por uma comunidade interpretativa. No caso do jornalismo, “A ocorrência é interpretada em função do código que a transforma em acontecimento jornalístico, descontextualizando-se”. (SODRÉ, 2009, p. 59). Um acontecimento singular para o medium é pautado, por exemplo, pela proximidade temporal e geográfica. Assim, também, 
um acontecimento que dure excessivamente no tempo perderá sua categoria de acontecimento. [...] $\mathrm{O}$ acontecimento tem uma data de validade, porque a variação, com o passar do tempo, transforma-se "no que é normal". [...] Nem todos os acontecimentos possuem o mesmo grau de obsolescência; em certos casos, um fato pode manter sua categoria de acontecimento em função das novas variações que sejam introduzidas sobre o primeiro acontecimento. (RODRIGO ALSINA, 2009, p. 141).

Uma ocorrência pode, portanto, ser reconhecida como acontecimento em determinados contextos e, em outros, não; ou ser categorizada como tal e, com o tempo, perder o "status". E, ainda, pode manter-se como acontecimento enquanto tiver elementos e novos fatos a acrescentar.

Todavia, para Quéré (1997), quando falamos em acontecimento, nos referimos a algo acabado, que se encontra no passado, ainda que recente. Enquanto ele acontece, parece-nos complexo e imprevisível; mas, ao seu fim e à luz de acontecimentos anteriores, reduzimos sua indeterminação. Conforme Quéré, o acontecimento é, ainda, uma coleção de micro-acontecimentos heterogêneos (inclusive, com extensões temporais diversas) que, quando qualificamos, sintetizamos e fazemos dela uma totalidade inteligível.

Finalmente, para Adriano Rodrigues (1993, p. 27), "é acontecimento tudo aquilo que irrompe na superfície lisa da história de entre uma multiplicidade aleatória de fatos virtuais.” Logo, distingue-se pela imprevisibilidade ou improbabilidade de ocorrência, por irromper "acidentalmente à superfície epidérmica dos corpos como reflexo inesperado, como efeito sem causa, como puro atributo.” (RODRIGUES, 1993, p. 29). Rodrigues explica ainda que, na antiguidade, tentava-se dominar esse caráter aleatório do acontecimento através de práticas de adivinhação. Hoje, porém, a principal forma de regulação dos fatos imprevisíveis é o discurso jornalístico, que tem por matéria-prima o acontecimento, mas cria para ele enquadramentos e categorias pré-determinadas. Com a transmissão televisiva ao vivo, os acontecimentos não apenas ganham um sentido público, mas são pré-dispostos ao conhecimento da audiência.

\section{O casamento real: um acontecimento mediático}

Programado, predefinido e previamente anunciado, o acontecimento mediático não é espontâneo, nem inesperado. Elihu Katz explica (1993, p. 53): "O assassinato de Kennedy foi notícia; o seu funeral foi um acontecimento mediático.” Organizado para a transmissão ao vivo, tem um elemento de grande drama ou ritual. É enquadrado no tempo e no espaço e põe em destaque um grupo ou uma personalidade histórica. No entanto, "a característica principal dos acontecimentos mediáticos talvez seja a insistência comunitária em que uma pessoa deve abandonar outras funções e compromissos em favor da televisão.” (KATZ, 1993, p. 54).

O casamento do príncipe inglês William Arthur Philip Louis com Catherine Middleton (popularmente conhecida como “Kate Middleton"), na Abadia de Westminster, em 29 de abril de 2011, é um claro e recente exemplo de acontecimento mediático, pois se configurou como uma cerimônia própria aos meios de comunicação de massa, apesar de ter sido organizada fora dos media e por iniciativa independente deles.

O telespectador de todo o mundo ocidental foi convidado a interromper sua vida cotidiana para compartilhar daquela experiência coletiva, como vemos na chamada da rede Globo:

Nesta sexta, tem o casamento real. O mundo inteiro ligado na cerimônia que marca a união entre o herdeiro da família real britânica, o príncipe William, e Kate Middleton. E aqui na Globo, você acompanha esta grande festa direto de Londres. Nesta sexta, a partir das sete da manhã: Casamento Real. (YOUTUBE, 2011).

O mega-evento escapou a toda rotina e, por isso, se distinguiu de qualquer outra emissão habitual. Foi uma forma de irrupção que suspendeu o fluxo dos programas:

Afin de pouvoir les diffuser, toutes les chaînes ont annulé leur programmes réguliers. Malgré la poignée de stations qui réussit toujours à marquer son indépendance en diffusant d'autres programmes, l'événement s'assure un quasimonopole de l'attention. Dans le répertoire des 
formes télévisuelles, il est difficile d'imaginer effet d'annonce plus fort ${ }^{8}$. (DAYAN; KATZ, 1992, p. 5).

Sigamos usando o último casamento real britânico como exemplo de acontecimento mediático, conforme características descritas por Dayan e Katz (1992). Fascinação, respeito, unanimidade: são esses os principais efeitos. Se não o mundo, a Inglaterra parou para celebrar o casamento monarca e apagou, ao menos naquele dia, as vozes controversas ou conflituosas que se levantavam contra seu sistema político, confirmando que "ces événements jouent un puissant rôle d'intégration."” (DAYAN, KATZ, 1992, p. 10). Tal papel, reforçador da identidade nacional, é confirmado ainda pela função comemorativa e o teor memorialista que podem ser associados ao acontecimento - a exemplo da constante reprodução das imagens dos casamentos reais, principalmente o do príncipe Charles com Diana, pais do noivo, nas reportagens que precederam o principal acontecimento mediático britânico de 2011.

Ligados à ordem estabelecida (poder hegemônico), os organizadores do grande evento divulgam nele os valores consensuais que defendem: no caso observado, o sistema monárquico e a tradição cristã, principalmente. Contudo, seguem regras impostas pela cobertura ao vivo - de tal forma, que, dificilmente, conseguimos distinguir quem determinou o que. Mesmo porque, por outro lado, os jornalistas responsáveis por comentar o evento, via de regra, respeitam com deferências os protocolos e quase não expõem críticas sobre o que veem.

Jornalistas, bispos, consultores de moda e embaixadores foram convidados para comentar o casamento do príncipe William e Kate, mas as análises geralmente eram tímidas e as apreciações negativas quase inexistentes (ou exclusivas a amenidades, como a vestimentas e penteados). De forma geral, na cobertura ao vivo das redes de TV brasileiras, durante a cerimônia religiosa, reinou a tradução simultânea ou o silêncio. Em outros momentos, os comentários eram mais elogiosos que

\footnotetext{
8 "A fim de poder os difundir, todos os canais anularam seus programas regulares. Apesar do punhado de estações que consegue sempre marcar sua independência difundindo outros programas, o acontecimento consegue um quase-monopólio da atenção. No repertório das formas televisuais, é difícil de imaginar efeito de anúncio mais forte. (DAYAN; KATZ, 1992, p. 5; tradução nossa).

9 “esses acontecimentos desempenham um poderoso papel de integração.” (DAYAN; KATZ, 1992, p. 5; tradução nossa).
}

críticos, como podemos perceber nos exemplos de enunciados formulados durante a transmissão da Globo News: "Ele é discreto e ao mesmo tempo muito carismático” (referindo-se ao príncipe William); "O que eu implico mesmo é com esse cabelo, que é de um louro que não se usa mais há uns trinta anos” (referindo-se a Camilla Parker-Bowles, esposa do príncipe Charles); "Ela realmente [...] está belíssima”; "Ela tem brilho, ela tem luz" (referindo-se a Kate Middleton); "Realmente, é uma coisa que toma conta das pessoas, esse carinho, esse amor mesmo pela família real” (YOUTUBE, 2011a).

Quanto ao público, cabe agendar e aguardar a cerimônia previamente anunciada e fortemente publicizada. Para ele, é quase como uma obrigação assistir a tal espetáculo; afinal, acontecimentos como esses "Ils sont presque invariablement qualifiés d' 'historiques'. Ils réussissent à galvaniser de vastes audiences: une nation; plusiers; le monde entire."10 (DAYAN, KATZ, 1992, p. 9). Vejamos um exemplo de interpelação do telespectador para assistir ao acontecimento mediático, na chamada do Casamento Real da Rede TV:

Nesta sexta, o mundo vai parar para um casamento real. E você acompanha ao vivo a cobertura completa da união do príncipe William com Kate Middleton. É o começo de um conto de fadas contemporâneo: a transformação de uma plebeia em princesa. Acompanhe na íntegra todos os detalhes deste deslumbrante espetáculo que marcará um novo ciclo da monarquia britânica. É imperdível! Nesta sexta, ao vivo. A partir das seis da manhã, na Rede TV. (YOUTUBE, 2011b).

Pelo uso do pronome de tratamento "você" e do verbo no imperativo "acompanhe”, o telespectador é intimado a assistir ao casamento projetado como um "conto de fadas contemporâneo". Além disso, na perspectiva de o acontecimento mediático ser um momento histórico, "imperdível”, ele parece prometer um diferencial, uma mudança ou mesmo uma nova era: “deslumbrante espetáculo que marcará um novo ciclo da monarquia britânica” - ainda que, na verdade, apenas confirme os valores centrais daquela sociedade.

\footnotetext{
10 "Eles são quase invariavelmente qualificados como históricos. Eles conseguem galvanizar vastas audiências: uma nação; muitas; o mundo inteiro.” (DAYAN; KATZ, 1992, p. 9; tradução nossa).
} 
Entretanto, Dayan e Katz (1992, p. 22) defendem que "certains cérémonies ont une fonction intrinsèquement libératice. Bien qu’au départ elles puissent servir un projet hégémonique et être ouvertement conçues en vue du maintien d'un statu quo, ces cérémonies peuvent se révéler subversives."11 Os valores centrais da sociedade podem ser questionados, a partir de um acontecimento mediático, mas não necessariamente a situação conduzirá a uma institucionalização de normas alternativas. De qualquer forma, certa imprevisibilidade é mantida nesse tipo de acontecimento.

Une entité organisatrice complexe a eu le pouvoir de concevoir la cérémonie en fonction de sés propres valeurs. Ces valeurs seront-elles maintenues? Le caractère généralement consensuel des cérémonies télévisées n'empêche pas le surgissement, à chaque étape, de conflits spécifiques. L'événement progresse alors comme une suíte ininterrompue de cessez-le-feu, d'amendements et de compromis. Sa signification ne peut pas être imposée ${ }^{12}$. (DAYAN, KATZ, 1992, p. 80).

Apesar de tudo ser planejado e de a cobertura televisiva programar o ângulo certo para cada momento, qualquer coisa, a qualquer instante, pode ainda sair do controle. Por isso, a televisão acaba sendo uma grande aliada dos organizadores do evento, ao enquadrá-lo segundo a versão deles. Aliás, é justamente a intervenção de tal meio de comunicação que diferencia o acontecimento mediático contemporâneo das precedentes cerimônias públicas.

Graças à televisão e às novas tecnologias da informação, o casamento de William e Kate pôde ser transmitido em tempo real para todo o mundo. A cerimônia tradicional queria ratificar a manutenção do sistema monárquico, mas, ao mesmo tempo, chamou a atenção para suas fragilidades e mobilizou debates, por exemplo, sobre sua continuidade e sobre a pos-

\footnotetext{
11 "certas cerimônias têm uma função intrinsecamente liberatória. Mesmo que no início elas possam servir a um projeto hegemônico e serem abertamente concebidas em vista da manutenção do status quo, essas cerimônias podem se revelar subversivas.” (DAYAN, KATZ, 1992, p. 22; tradução nossa).

12 "Uma entidade organizadora complexa teve o poder de conceber a cerimônia em função de seus próprios valores. Esses valores serão mantidos? O caráter geralmente consensual das cerimônias televisivas não impede o surgimento, a cada etapa, de conflitos específicos. O acontecimento progride então como uma seqüência ininterrupta de cessar fogo, de emendas e de compromissos. Sua significação não pode ser imposta." (DAYAN, KATZ, 1992, p. 80; tradução nossa).
}

sibilidade de o trono ser passado diretamente para o príncipe William, sem a sucessão de seu pai, o príncipe Charles.

Como as cerimônias televisivas não são isentas de imprevistos, os interesses dos três principais parceiros (os organizadores, os media e os telespectadores) podem divergir e as tensões precisarão ser negociadas antes que o espetáculo chegue ao público. Na negociação do contrato, qualquer um pode sair perdendo. As expectativas de uma das partes podem ser parcialmente negadas, o contrato rejeitado ou violado. Um exemplo disso, apresentado por Dayan e Katz (1992), é o dos Jogos Olímpicos. As proezas individuais dos jogadores eram as tradicionalmente celebradas nesse grande evento mundial, até que os media acentuaram a competição entre as nações. Os organizadores deixaram de ser soberanos. "En prenant la mesure des possibilites offertes par les direct, ceux-ci acceptent de perdre toute maîtrise exclusive sur l'événemnt." ${ }^{13}$ (DAYAN, KATZ, 1992, p. 77).

Finalmente, conclui-se que a performance da televisão altera significativamente a natureza do acontecimento. Justifica o que ele tem de singular, mostra seu potencial de ruptura e naturaliza as intenções dos organizadores. É este medium também que faz valer as regras do jogo: “La télévision sert ici d'ange gardien, protege au nom du 'tact' ou du 'bom goût' la version officielle de l'événement." ${ }^{14}$ (DAYAN, KATZ, 1992, p. 83). Por isso, alguns autores não concordam que esse tipo de evento seja chamado de "acontecimento", como demonstraremos $\log$ a seguir.

\section{A tese da degradação do acontecimento em fato}

Para Claude Romano (1998), o acontecimento coberto pela imprensa é reduzido a fato, pois não é autêntico, mas sim um produto de massa que neutraliza qualquer radical novidade. Segundo o autor, mesmo que em nossa época a forma dominante de

\footnotetext{
13 "Tendo em conta as possibilidades oferecidas ao vivo, estes aceitam perder todo controle exclusivo sob o acontecimento.” (DAYAN, KATZ, 1992, p. 77; tradução nossa).

14 “A televisão serve aqui de anjo guardião, protege em nome do 'tato' ou do 'bom gosto’ a versão oficial do acontecimento.” (DAYAN, KATZ, 1992, p. 83; tradução nossa)
} 
se conhecer os acontecimentos seja a narrativa mediática, o acontecimento jornalístico apenas oferece um simulacro de experiência para seus públicos. Ele defende a ideia de que o acontecimento jornalístico é desenraizado, não possui relações significativas com outros acontecimentos e sobrevêm a todos e a ninguém ao mesmo tempo - por meio da interpelação de conjuntos neutros, categorias sociais ou entidades genéricas (sindicato, cidadão, consumidor etc.):

Rapportés par la presse écrite ou audiovisuelle, véhiculés sous forme d'informations', ces événements apparaissent, au contraire, dépourvus de toute assignation spécifique: ils s'adressent à tout le monde et à chacun, c' est-à-dire, proprement, à personne - à un 'tout le monde' générique qui signifie, fondamentalement: personne en

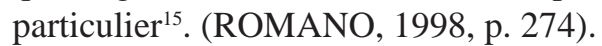

Romano argumenta que o acontecimento mediatizado, como todo produto de massa, fica disponível para todos, mas não pertence a ninguém; visa à novidade, mas responde a uma cronologia repetitiva e sem surpresa; é subordinado pela periodicidade do medium e sua radicalidade é neutralizada com comentários explicativos. Assim, para Romano, a mediatização degrada o acontecimento em "simples fato”, considerado como elemento do seu sistema de produção de informações. Os media tentam explicá-lo, sem nem mesmo compreendê-lo, e não medem esforços para analisar suas causas, ainda que arbitrariamente.

Não importa a tecnologia empregada, explica o autor. Para ele, os novos meios de comunicação só acentuam a poeira de acontecimentos sem consistência própria, rapidamente esquecidos e, por isso mesmo, incapazes de oferecer ao homem uma real experiência.

Na mesma linha de Claude Romano, Jocelyne Arquembourg-Moreau (2003) questiona se os “acontecimentos históricos em tempo real” (como o casamento de William e Kate) seriam realmente acontecimentos: os acontecimentos mediáticos seriam capazes de organizar no plano coletivo uma ex-

\footnotetext{
15 “Trazidos pela imprensa escrita ou audiovisual, veiculados sob forma de ‘informações', esses acontecimentos aparecem, ao contrário, desprovidos de toda atribuição específica: se endereçam a todo mundo e a cada um, ou seja, propriamente, a ninguém - a um 'todo mundo' genérico que significa, fundamentalmente: ninguém em particular.” (ROMANO, 1998, p. 274, tradução nossa).
}

periência comparável a dos planos biográfico e histórico? O regime de temporalidade da transmissão ao vivo seria compatível com o que entendemos por acontecimento histórico e acontecimento público?

Para Arquembourg-Moreau, na transmissão dos grandes acontecimentos cuja cobertura ao vivo asseveraria a experiência de vivenciar um momento histórico,

L’historicité décrétée d'avance anticipe le regard des générations futures tournées vers un passé qui est notre présent. [...] Ce mode d'apréhension du temps et des événements est loin de correspondre à ce que la phénomenologie définit par le concept d'événement ${ }^{16}$. (ARQUEMBOURG-MOREAU, 2003, p. 26).

Pensando o conceito fenomenológico de acontecimento (explanado na primeira parte deste artigo), a autora afirma que todo acontecimento requer produção de sentido, mas que a sua inserção num texto o encarcera e o descaracteriza, pois explicar é ordenar e ele é ruptura e desordem: "Les médias sont toujours confrontés à une demande d'information qui est aussi une demande de sens et donc à l'impérieuse necessité d’insérer les événements dans la trama logique d'une histoire qui les explique."17 (ARQUEMBOURG-MOREAU, 2003, p. 33).

Por outro lado, o fato é causa, contexto e explicação. Logo, para a autora, ao se tentar reduzir a contingência incompreensível do acontecimento público, a elucidação a ele atribuída o transformaria em fato. Assim, o fato seria o acontecimento explicado, contextualizado, observado e narrado conforme uma linha coerente. Resumindo, conforme Arquembourg-Moreau, o acontecimento mediático não seria propriamente acontecimento, mas fato.

Eventos como a cerimônia matrimonial britânica do príncipe William são propagados antes de acontecerem e minuciosamente explicados quando transmitidos - o que poderia descaracterizá-los como acontecimentos. Além disso, como os fatos,

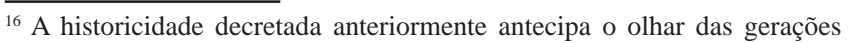
futuras voltadas para um passado que é nosso presente. [...] O modo de apreensão do tempo e dos acontecimentos está longe de corresponder ao que a fenomenologia define pelo conceito de acontecimento. (ARQUEMBOURG-MOREAU, 2003, p. 26, tradução nossa).

17 “Os media são sempre confrontados a uma demanda de informação que é também uma demanda de sentido e, então, à imperiosa necessidade de inserir os acontecimentos na trama lógica de uma história que os explique.” (ARQUEMBOURG-MOREAU, 2003, p. 33, tradução nossa).
} 
apenas projetam valores pré-construídos e consensuais, frequentemente legitimadores do status quo, ao passo que o irromper de um verdadeiro acontecimento criaria a perspectiva de um novo mundo, esclarece Arquembourg-Moreau.

A autora pontua ainda que a mediatização parece intrínseca ao acontecimento no momento de sua emergência e o significado deste é dado como pronto. No entanto, como o vento, o sentido do acontecimento sempre pode mudar.

Le public se trouve ainsi projeté dans l'histoire comme s'il ne devait pas y avoir de décalage entre l'interprétation contemporaine de l'événement et son interprétation future. Mais c'est oublier que les événements historiques sont interprétés aussi sous la description d'une présent. (...) Non seulement l'interprétation des événements présents mais aussi la qualification même d'historique n'est pas assurée de manière definitive, sauf à vouloir figer le processus temporel même qui circule à traves l'histoire. L'histoire en temps réel serait un peu comme l'histoire sans le temps de l'histoire ${ }^{18}$. (ARQUEMBOURG-MOREAU, 2003, p. 49).

Interpretamos o acontecimento no presente, o julgamos como histórico e acreditamos que tal julgamento será unânime e imutável. A circulação do mesmo vocabulário usado para descrevê-lo, das mesmas imagens e das mesmas referências contribui para a formação de um ponto de vista comum sobre os fatos. Contudo, esquecemo-nos que, futuramente, quando ele parecer completo e suas relações com outras ocorrências mais bem determinadas, o compreenderemos diferentemente.

Não é o tempo real do acontecimento mediático que indicará o surgimento de uma nova época e sim o resultado de um processo, analisado posteriormente. Afinal, a qualificação de histórica é devida à marcação de "la fin ou une étape importante d’un processus dans lequel une communauté se sent

\footnotetext{
18 "O público se encontra assim projetado na história como se não houvesse defasagem entre a interpretação contemporânea do acontecimento e sua interpretação futura. Mas isso é esquecer que os acontecimentos históricos são interpretados também sob a descrição de um presente. [...] Não somente a interpretação dos acontecimentos presentes, mas também a própria qualificação de histórico não é assegurada de maneira definitiva, exceto por querer condensar o processo temporal que circula através da história. A história em tempo real seria um pouco como a história sem o tempo da história.” (ARQUEMBOURG-MOREAU, 2003, p. 49, tradução nossa).
}

engagée."19 (ARQUEMBOURG-MOREAU, 2003, p. 50). É o virar de uma página.

A história estuda o que faz com que comunidades ou nações se identifiquem com determinado acontecimento do passado. Os media fazem com que o público viva o acontecimento agora, voltando-se para o futuro e nele projetando suas expectativas e aspirações:

Le rôle du futur émerge de manière décisive de la temporalité des événements médiatiques en direct. Loin de correspondre au schéma rétrospectif des événements historiques, ils semblent bien plutôt constitués à partir de lignes de fuite orientées vers l'avenir. (...) On constate que le travail de mise en intrigue effectué par le réalisateur s'appuie à la fois sur une forme d'antecipation, une projection dans le futur et sur la prise en compte des attentes et des habitudes du public ${ }^{20}$. (ARQUEMBOURG-MOREAU, 2003, p. 51).

Isso não quer dizer que a cobertura de um grande acontecimento paire apenas sobre o presente e o futuro, pois, como facilmente se pode constatar, os meios de comunicação sempre dispõem de narrativas retrospectivas para tentar esclarecê-lo. Mas essa temporalidade passada é apenas um tipo de muleta de sustentação do presente e de algumas projeções do futuro, que são os tempos enfatizados pelos media.

Por fim, apesar de defender a descaracterização do acontecimento por sua mediatização e de observar que o regime de temporalidade da transmissão ao vivo não é compatível com o que entendemos por “acontecimento histórico", Arquembourg-Moreau elucida:

les événements médiatiques sont susceptibles de faire émerger des publics capables d'intervenir dans la constituition de problèmes qui peuvent aboutir à une demande d'action publique. L'expérience publique dont il est question

\footnotetext{
19 "do fim ou de uma etapa importante de um processo no qual uma comunidade se sente engajada.” (ARQUEMBOURG-MOREAU, 2003, p. 50, tradução nossa).

20 “O papel do futuro emerge de maneira decisiva na temporalidade dos acontecimentos mediáticos ao vivo. Longe de corresponderem ao esquema retrospectivo dos acontecimentos históricos, eles parecem bem mais constituídos a partir de linhas de fuga orientadas para o futuro. [...] Constata-se que o trabalho de narração efetuado pelo realizador se apóia ao mesmo tempo sobre uma forma de antecipação, uma projeção no futuro e sua consideração das expectativas e hábitos do público.” (ARQUEMBOURGMOREAU, 2003, p. 51, tradução nossa).
} 
s'accomplit donc en deux temps. Dans un premier temps, des événements médiatiques provoquent l'émergence de publics, dans un second temps, des efforts d'appropriation sont déployés tant par des acteurs que par les médias ou les publics pour répondre aux événements ${ }^{21}$. (ARQUEMBOURG-MOREAU, 2003, p. 101).

A autora parte do princípio da não receptividade pacífica por parte da audiência, mas da sua apropriação dos fatos para a participação em "arenas públicas”. Esclarecemos que o público é formado quando um grupo de pessoas é confrontado com uma situação ou uma ocorrência que o afeta e que nele faz surgir um interesse comum. Então, os acontecimentos mediáticos podem não ser capazes de produzir uma experiência no telespectador igual à que ele viveria se os testemunhasse pessoalmente, mas suscitam o debate sobre problemas públicos.

Como vimos, o acontecimento mediático beira um simulacro do fato em tempo real, pois busca o consenso, o fechamento, a explicação, o já feito antes mesmo de se fazer. Ainda assim, há a possibilidade do desvio, há o acento do singular e da ruptura. $\mathrm{O}$ casamento real foi muito bem elaborado e auxiliado pelos media, para a manutenção do consenso nacional, mas gerou questionamentos no público e aquele poderia ter sido um momento de discordâncias fatais em relação ao regime monárquico.

Discordamos, por isso, da tese de que a mediatização não daria conta do acontecimento, por não poder constituir uma experiência pública. O acontecimento mediático pode não ter a mesma repercussão do drama pessoal, mas não deixa de ecoar sob a audiência, pois marca um antes e um depois na sua percepção da temporalidade e cria um vínculo com o telespectador que se sente tocado pelo acontecido. Não podemos esquecer que um mesmo evento pode ser considerado acontecimento para certo segmento, mas não para outro. $\mathrm{O}$ casamento real pode ter passado despercebido, por exemplo, para habitantes de países árabes que em nada se sentiam concernidos

\footnotetext{
21 “os acontecimentos mediáticos são suscetíveis a fazer emergir públicos capazes de intervir na constituição de problemas que podem conduzir a uma demanda de ação pública. A experiência pública que está em questão se completa em dois tempos. No primeiro tempo, os acontecimentos mediáticos provocam a emergência de públicos; num segundo tempo, esforços de apropriação são empregados tanto pelos atores quanto pelos media ou pelos públicos, para responder aos acontecimentos.” (ARQUEMBOURGMOREAU, 2003, p. 101, tradução nossa).
}

pelo evento televisionado, mas não para o mundo ocidental, acostumado com as narrativas dos contos de fadas e embalado pelo sonho de um matrimônio monogâmico e feliz. Portanto, defendemos que mesmo o acontecimento mediático possibilita uma experiência pública, quando os telespectadores acrescentam à sua agenda as discussões em torno do tema e reagem a ele - o que é, para nós, uma forma de enraizamento do acontecimento na vida dos indivíduos.

\section{Considerações finais: a construção discursi- va do acontecimento}

É interessante observar que Arquembourg-Moreau não chama o fenômeno estudado de fato mediático, assim como Claude Romano não o faz. Eles conservam o título de acontecimento mediático ou jornalístico, mesmo admitindo sua descaracterização. Defendemos aqui a manutenção de tal nomenclatura, por um motivo simples: ainda que descaracterizado, o “acontecimento histórico em tempo real” é construído para que o telespectador sinta como se estivesse diante do próprio evento e os efeitos de sentido produzidos o aproximam do que entendemos por "acontecimento".

Dominique Charaudeau (2006, p. 132) assevera: "Para que o acontecimento exista é necessário nomeá-lo. O acontecimento não significa em si. O acontecimento só significa enquanto acontecimento em um discurso.” Portanto, ele não deve ser pensado como um dado preexistente, mas já como um resultante dos processos de produção de sentido. Afinal, "não existe referência fora do discurso porque é o discurso que constrói sua própria referência.” (TÉTU, 2002, p. 197).

De acordo com Vera Regina Veiga França (2002, p. 488), "se o acontecimento é um traumatismo do sentido na esfera do real e só ganha corpo através de um dispositivo narrativo, ele se torna inseparável de seu próprio relato.” A partir da dinâmica do real, o evento é inserido no jornal, mas é o discurso jornalístico que intervém e constrói o acontecimento, ao selecioná-lo e narrá-lo, explica a autora.

Sobre o aspecto dos media como um dispositivo de produção do acontecimento ou como uma instância construtora da realidade, Fausto Neto corrobora: “o poder das mídias está na sua capacidade de construir - via discursos - conceitos e referências 
que, em última análise, vão se tornando o nosso próprio cotidiano.” (FAUSTO NETO, 1999, p. 9). A narrativa cria aquilo que narra e o acontecimento reconstituído mediaticamente realiza-se num movimento de espaço e tempo próprio da narrativa.

Logo, o acontecimento se concretiza para a audiência no discurso mediático. É por meio deste que o acontecimento lhe chega; é na materialidade da sua enunciação, que ele se torna real. Dessa forma, ao ser construído como acontecimento singular, cujo potencial de ruptura marca um antes e um depois, são esses efeitos de sentido que farão dele mais do que um simples fato. $\mathrm{O}$ acontecimento mediático é produzido para não passar despercebido e ele chega a fazer parte da vida dos telespectadores como uma ocorrência pessoal o faria. Nesse sentido, é acontecimento, pois foi produzido e recepcionado como tal.

\section{Referências}

ARQUEMBOURG-MOREAU, Jocelyne. Le temps des événements médiatiques. Bruxelles: De BoeckUniversité, 2003. (Col. Médias recherches).

CHARAUDEAU, Patrick. Discurso das mídias. Tradução Ângela S. M. Corrêa. São Paulo: Contexto, 2006.

DAYAN, Daniel; KATZ, Elihu. La télévision cérémonielle: antropologie et histoire. Paris: Presses Universitaires de France, 1992.

FAUSTO NETO, Antonio. Comunicação e mídia impressa: estudo sobre a Aids. São Paulo: Hacker, 1999.

FRANÇA, Vera Regina Veiga. Construção jornalística e dizer social. In: MOUILLAUD, Maurice; PORTO, Sérgio Dayrell (Org.). O jornal: da forma ao sentido. 2. ed. Brasília: UNB, 2002. (Coleção Comunicação, 2).

KATZ, Eliu. Os acontecimentos mediáticos: o sentido de ocasião. In: TRAQUINA, Nelson (Org.). Jornalismo: questões, teorias e estórias. Lisboa: Vega, 1993. p.52-60.

MOLES, Abraham. Notes pour une typologie des événenents. Communication, Paris, Seuil, n. 18, p. 90-96, 1972.

MOLOTCH, Harvey; LESTER, Marilyn. Informer: une conduite délibérée. Reseaux: communication technologie societé (CNET), n. 75, p. 25-41, jan./fev. 1996.

MORIN, Edgar. Le retour de l'événement. Communication, Paris, Seuil, n. 18, p. 6-20, 1972a.

. L'événement sphinx. Communication, Paris, Seuil, n. 18, p.173-192, 1972b.

NORA, Pierre. L'événement monstre. Communication, Paris, Seuil, n. 18, p. 162-172, 1972.
QUÉRÉ. Louis. L'événement. In: BEAUD, Paul et al. (Dir.). Sociologie de la communication. Paris: Reseaux / CNET, 1997. p.413-540.

RICOEUR, Paul. Événement et sens. In: PETIT, Jean-Luc (Dir.). Raisons pratiques: l'événement en perspective. Paris: Ehess, 1991.

RODRIGO ALSINA, Miquel. A construção da notícia. Tradução Jacob A. Pierce. Petrópolis: Vozes, 2009. (Coleção Clássicos da Comunicação)

RODRIGUES, Adriano Duarte. O acontecimento. In: TRAQUINA, Nelson (Org.). Jornalismo: questões, teorias e estórias. Lisboa: Vega, 1993. p. 27-33.

ROMANO, Claude. L'événement et le monde. Paris: Presses Universitaires de France, 1998. (Épiméthée).

SODRÉ, Muniz. A narração do fato: notas para uma teoria do acontecimento. Petrópolis: Vozes, 2009.

TÉTU, Jean-François. Le Monde e Libération em perspectiva: referências e significação: Le Monde. In: MOUILLAUD, Maurice; PORTO, Sérgio Dayrell (Org.). O jornal: da forma ao sentido. 2. ed. Brasília: UNB, 2002. p.191-201. (Coleção Comunicação, 2).

YOUTUBE. Casamento Real: chamada Globo. Disponível em: <http://www.youtube.com/watch?v=oGB5kvVzkA0>. Acesso em: 01 jun. 2011.

Melhores momentos do casamento Real. Disponível em: http://www.youtube.com/watch?v=rf7JfXReNk o\&feature=related. Acesso em: 01 jun. 2011a).

Promo casamento Real - RedeTV! Disponível em: $<\mathrm{http}$ ://www.youtube.com/watch?v=wx5WsCiGpVM>. Acesso em: 01 jun. 2011b).

Recebido em: 20 de abril de 2012 Aceito em: 27 de agosto de 2012 